Harry van der Hulst, Maarten Mous \& Norval Smuth

\title{
The autosegmental analysis of reduced vowel harmony systems: the case of Tunen
}

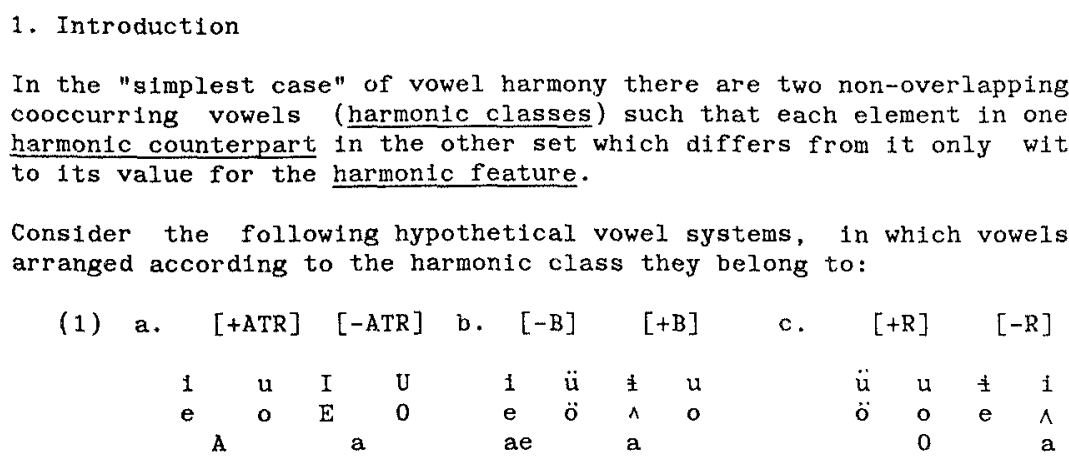

We refer to these systems as full systems and to vowel harmony based on such systems as full harmony. I

The treatment of full harmony systems is trivial and not very interesting. Fortunately, most cases, of vowel harmony are not so simple. Usually the complications have arisen due to the fact that some combinations of phonological properties tend to be avoided, which eventually has lead to a language specific constraint against these combinations and, consequently, mergers among vowels. 2

Let us consider possible examples of what are called reduced systems. Next to a full Advanced Tongue Root (ATR) systcm, as in (1a) one commonly finds systems as in (2):
(2) a. $[+\mathrm{ATR}]$
$[-\mathrm{ATR}]$
b. $[+\mathrm{ATR}]$
$[-\operatorname{ATR}]$

$\begin{array}{lllll}1 & u & I & \text { U } \\ \text { e } & & \text { o } & \text { E } & \\ & - & & & a\end{array}$

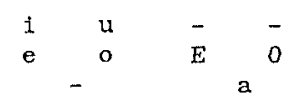

Dashes indicate gaps in the system. Similarly, common reduced palatality systems are: 
(3) a. $[-B]$ $\begin{array}{ll}1 & \ddot{u} \\ \mathrm{e} & \ddot{o} \\ \mathrm{ae} & \end{array}$

$$
[+B]
$$$$
-\mathrm{u}
$$

a b. $[-\mathrm{B}]$

$[+\mathrm{B}]$

$\begin{array}{cccc}\mathbf{i} & \ddot{u} & - & u \\ \mathbf{e} & \ddot{o} & - & \text { o } \\ - & & \text { a } & \end{array}$

Reduction in rounding systems is not exemplified here. Stewart (1971) provides a functional explanation for the fact that the systems as exemplified in (2) occur so frequentiy. The vowel /A/ on the one hand and the vowels /I, U/ on the other, are the most commonly eliminated by sound changes, because they involve "the most awkward of the combinations of points on the low/mld/high scale with points on the root-unadvanced/root-advanced scale as the root naturally tends to be pushed backwards when the highest part is low and pulled forwards when the highest part is high." (Stewart,1971:199). With respect to reduced palatality systems the validity of the same reasoning is obvious, given the markedness of unrounded back nonlow vowels.

Reductions in the vowel inventory lead to complications in the harmony systems in that alternations are either neutralized or changed in character. To illustrate this let us consider in some detall the reductions in [ATR] systems.

There are various ways in which the vowels /A/ and /I, U/ may be lost. The fact that they involve awkward combinations of phonological properties does not yet imply that they should change according to one set rule. One expects that the marked vowles will merge with vowels which are either articulatorily or acoustically "close" to them. For the low vowel this implies that it will merge with some non-high vowel, and for the high vowels that they will merge with some non-low vowel.

Wliliamson $(1973,1984)$ who describes a varlety of reduced systems, represents a. full ten vowel system as follows:

(4)

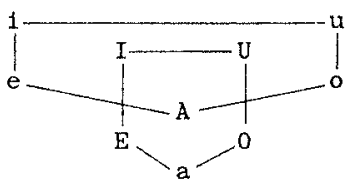

In Williamson's papers and others dealing with reduced systems, the following routes by which /A/ may merge with other segments are reported:

(5)

$$
\text { C }
$$

As for the high vowels /I/ and /U/, the following routes are found to occur:

(6)

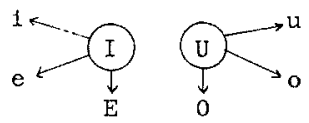

In (7) we give a list of the mergers which are exemplified in (5) and (6) with an indication of the synchrontc consequences for the alternations: 3 
(7)

Change in class

$$
\left\{\begin{array}{l}
\text { Change In height } \\
|\mathrm{A} / \rightarrow| \mathrm{E} /, / \mathrm{O} / \\
|\mathrm{I} /, / \mathrm{U} / \rightarrow| \mathrm{e} /, / \mathrm{O} / \\
\text { No change in height } \\
|\mathrm{A}| \rightarrow|\mathrm{a}| \\
|\mathrm{I} /,| \mathrm{U} / \rightarrow \mid \mathrm{i} /, / \mathrm{U} /
\end{array}\right.
$$

Alternation

$$
\begin{array}{ll}
|a|-|E| \text { (a) } \\
|a|-|b| \text { (b) }
\end{array}
$$$$
|1|-|e| \text { (c) }
$$$$
1 \mathrm{u} / \mathrm{H} / \mathrm{d})
$$

neutralized (e)

neutralized $(f)$

No change in class Change in height

$$
\begin{aligned}
& |A| \rightarrow \mid e /, 10 / \\
& |a|-|e|(g) \\
& 1 \mathrm{a}-101 \quad(\mathrm{~b}) \\
& |\mathrm{I} /, / \mathrm{U} / \rightarrow| \mathrm{E} /, / 0 / / 1 /-/ \mathrm{E} / \text { (i) } \\
& / \mathrm{u} / \mathrm{l} / \mathrm{l} / \mathrm{j})
\end{aligned}
$$

The above scheme implies a classiflcation of the different routes into three groups. If an awkward vowel merges, it either falls together with a vowel within the other harmonic class, or it falls together with a vowel belonging to its own class (necessarliy of a different height). In the first case it either falls together with its harmonic counterpart or with a vowel of a different helght. In (8) we 11lustrate the possibilities; taking the marked vowel/I/ as an example.

(8) $/ I / \rightarrow / 1 /$ (f) Alternation $/ 1 /-/ 1 /$ is neutralized

$$
\begin{aligned}
& / I / \rightarrow / \text { (c) Alternation /I/ }-/ 1 / \text { is changed to /e/ }-/ I / \text { i.e. } \\
& \text { the ATR difference is replaced by a height difference. }
\end{aligned}
$$

a height difference is added to the ATR difference

That the complications for the harmony system are different is easy to see. In tre first case we will get disharmony effects, since the instance of the vowel /1/ which derives from */I/ w111 now cooccur with [-ATR] vowels. In the third case no disharmony results, but we do get the complication of having an "extra" change in helght. The second case combines both complications, 1,e. disharmony results since some /e/'s will cooccur with [-ATR] vowels and the extra height alternation is present as well'r

The first case (in which an alternation is neutralized leading to disharmony effects) has explicitiy been noled in the descriptive literature on vowel harmony. Vowels which have been merged with their harmonic counterpart have often been called neutral. One must be careful, however, to distinguish two kinds of neutral vowels. In one type of case the neutral vowels appear to be transparent in the sense that the harmonic requirement, as it were, looks right through them, 1.e. rowels occurring to the left of these transparent vowels must harmonize with vowels to the right (and vice versa), just as if the neutral segments were not there. Suffix vowels which are adjacent to a transparent vowel or.curring in the final syllable of the ster harmonize with the first non-transparent vowel to its left, Ignoring the fact that the transparent vowel intervenes. In the other type of case the neutral vowels are opaque, 1.e. it is not necessary that vowels occurring on either side harmonize with each other. Also, suffix vowels which are adjacent to an opaque vowel harmonize with 1 t. 5

The second and third case have recelved less explicit attention, as far as we know, not even at the terminological level. 


\section{Theoretical framework}

The issue of dealing with disharmony effects (1.e. neutral vowels) is discussed at length in Van der Hulst and Sm1th (1986a), hencefort HS. The focus of this paper is on the treatment of (extra) height alternations, although our examples also involve disharmony effects. Before we study this case in some detall we will give an outline of the theoretical framework adopted by us.

\subsection{The representation of neutral vowels}

From the outset, opaque and in partlcular transparent vowels have been problematic for earlier versions of autosegmental phonology. As an essential characteristic of this model we take the fact that each feature is represented on one tier only.

The impression that vowels agree in harmonlc value across a third vowel which has an opposite value has seduced several phonologists into abandoning this essential characteristic, and this, in our view, obscures one of the most fundamental insights on which autosegmental theory 1s based. In many publications, including some of our own (Van der Hulst and Smith 1982, Boo1j 1984, Ewen and Van der Hulst 1985, Vago 1984, Lieber 1985) 1t is proposed that we should allow for the possibility of specifying a single feature on more than one tier. Let us refer to this as the posstbility of having tier duplication. The details of the various proposals certainly differ, but they all boil down to the 1dea that vowels which are transparent are segmentally spec1f1ed, such that a morpheme level autosegment can spread across them. 6

We believe that tier duplication must be avolded for two reasons. Firstly, we belleve that, all things being equal, we should prefer the phonologlcal model which comes closest to phonetic reality. This is in fact what Postal's Naturalness Condition says. From this perspective it seems that as long as human beings have one tongue root, we should allow just one tongue root tier in our model. Secondly, it w1ll be obvious that tier duplication increases the descriptive power of the model and thus should only be allowed if no other possibilities remain. In Van der Hulst and Smith (1986a) an account is proposed which makes no use of tier duplication. 7

HS adopt a single-valued feature approach in which the universally marked pole of phonological features is represented as the lexical value. The opposite value results from phonetic interpretation, and is called the default value HS furthermore adopt a view that all features which are not involved in an alternation must be underlyingly specified. In accordance with this view, neutral segments which have the lexical value require the presence of this value in their morphemic representation. In Hungarian for example, which has backness harmony, transparent segments would be specified in the lexical stratum as associated to the harmonic feature and in this sense they are accessible vowels, just Itke the normal harmonizing vowels. The difference between harmonizing and transparent vowels is that the latter are inherently specifled. A cruclal property of transparent segments 1s that they do not spread, i.e. they do not impose their value on neighbouring vowels. HS therefore adopt an 1dea first advanced by Halle and Vergnaud, namely that the untversal association conventions ( $A C^{\prime} S$ ) only apply to floating autosegments. If we accept this, we can represent words with a neutral vowel as in (9). 
(9)

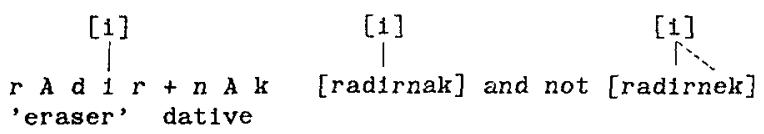

The two vowels stradding the neutral vowel will acquire the default value and the correct surface form will be derlved. HS explain why transparent vowels in suffixes "let through" the [1] value if they are preceded by a floating instance of [1] by appealing to the obligatory Contour Principle (OCP). The relevant situation arise in the following example (cf. 10a). The configuration in (10a) is interpreted as an OCP violation and HS assume a convention which turns it into $(10 \mathrm{~b}) 9$.

(10)
a. $[1]$
[1]
b.
[1]
$[1]$
$\mathrm{T} \mathrm{I} \mathrm{b}+1+\mathrm{nAk}$
$T I b+I+n A k \rightarrow[t i b i n e k]$
(petname on the bals of the name Tibor).

Observe that this proposal seems to presuppose that the AC's can distinguish between derived and underlying association ines, but this is not necessary if we assume that $\mathrm{AC}$ 's apply post-cyclically.

It is of some 1mportance to realize that neutral vowels which have the lexical value may under spectal circumstances act harmonically. This happens for example in so called neutral vowel morphemes where we find the following contrast:
(11) a. [1]<smiles></smiles>

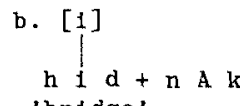<smiles>[AlH2]</smiles>
$\mathrm{vIz}+\mathrm{nAk} \rightarrow$ [viznek] 'bridge' 'water'

(11) may arise since independent from the inherent specification of neutral vowels roots are specified as elther front ([1]) or back (0). This results in the logical possibility of the existence of front roots with only neutral vowels which cannot be represented as in (12 a or b) but must be represented as in (11a) as required by the $0 \mathrm{CP}$ :

a.<smiles>[AlH][AlH2]</smiles><smiles>[AlH2][AlH2]</smiles>

The representation in (11a) will trigger application of the AC's, which means that the /I/ in /VIz/ sets off its own harmonic domain and can thus not be regarded as transperent. The lesser formal complexity of (11a) suggests that morphemes having any neutral vowels should preferably behave as non-transparent (1.e. harmonic) rather than as transparent.

Although neutral segments which have the lexical value can behave either transparently or opaquely neutral segments having the default value seem to behave consistently opaquely. 8 Let us now turn to the formal representation of opac1ty. 
Opacity includes, among others, the representation of disharmonic roots. In current approaches disharmonic roots are represented as follows:

$$
\text { (13) }\left.\right|_{\text {bur } 0} ^{[1]}+\text { nAk } \rightarrow \text { [buronak] kosztum }+ \text { nAk } \rightarrow \text { [kosztumek] }
$$

As shown, the [1] of the second example must spread to the suffix. Yet we represented it as underlyingly linked. The inevitable conclusion is that if we use lexical association lines for transparent vowels, we cannot use the same mechanism for opaque vowels. In order to solve the problem of representing disharmonic roots, we should like to say that the [1] autosegment is floating, but includes only one of the root vowels in its scope.

It has been shown that there are cases where the autosegments are bound to particular prosodic categories other than the phonological word without being assoclated to elements in these categorles. Examples Involve autosegments spreading within the syllable or the foot. We will claim that the smallest prosodic category is a category which comprises a single skeletal point. We call it the segmental domain.

Since the prosodic hierarchy forms an independent plane in a three-dimensional phonological representation, 1mposing limitations on the spreading of an autosegment involves the projection of a prosodic category $P$ onto the relevant tier. Hence we will say that in disharmonic roots the segmental domain is projected onto the harmonic tier. This of course results in a situation in which an autosegment may both be floating and segmentally bound. We represent this situation as follows:

(14)

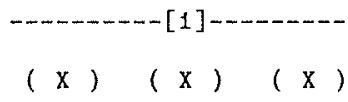

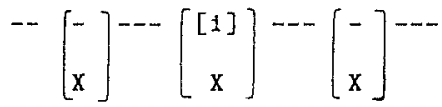

Prosodic domains projected onto an autosegmental tier create a "one-way" opacity: you cannot go in, but you can get out.

The mechanism of segmental binding gives us a complete formal account of opacity. We can use it for example to deal with the opac1ty of low vowels in Akan. Low vowels in Akan are always [-ATR], whlch 1 s the default value. In the lexical derivation the following constraints holds (cf. 15a):

(15)

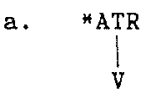

b.

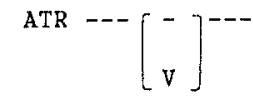

We assume that (15a) automatically imlies (15b) fust in the case the vowel at issue belongs to the set of harmony-bearing units. If a particular harmony-bearing unit cannot become assoclated to the harmonizing feature, it will automatically be opaque in the sense just proposed. In other words it is inaccessible to the lexical value. In cases of this type opacity is predictable on phonological grounds, which is not the case in disharmonic roots where the opacity is an idiosyncratic property of particular morphemes. 
22 Underspecification

said above, we assume a single-valued tridirectional feature system (cf. ..n and Van der Hulst 1985). For our analysis we only need to mention a subset of the features which are relevant for vowels:

(16) VOCALIC FEATURES

$[1],[\mathrm{u}],[\mathrm{a}],[\mathrm{A}]$

A skeletal point assoclated to the feature [A] (1.e. [A(dvanced tongue root)]) s phoneticaliy interpreted as tongue root advanced, whereas skeletal points not associated to [A] are Interpreted as tongue root unadvanced. We use the ierm default value for the phonetic interpretation of the absence of a phonological feature.

A point assoclated to each of these features separately results in a "pronounceable" segment. We wlll refer to the vowel segments as $/ 1 /$, $/ \mathrm{u} / \mathrm{etc}$.

(17)

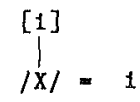

A ten vowel system comprising five advanced and five unadvanced vowels is represented as in (18). Since no confusion is possible, we represent features in diagrams without square brackets:

(18)

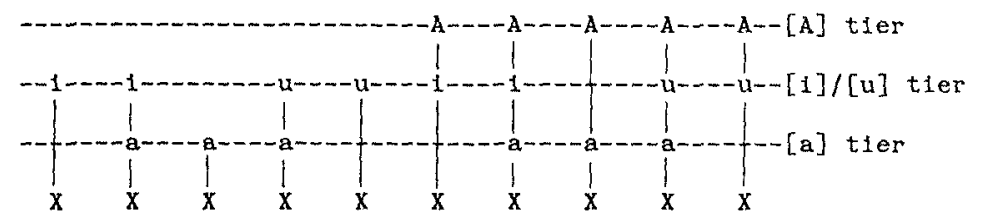

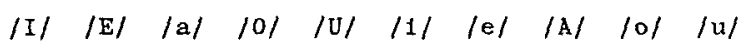

The notation used here to represent phonologlcal representations resembles that of Kaye, Lowenstam and Vergnaud (1985). Tiers are plied on top of each other, which is purely for graphical convenlences, and not meant as expressing the idea of coplanar features (cf. Archangeli 1985). Notice that the feature [1] and $[u]$ occur on the same tier. We take over an idea of Kaye, Lowenstamm and Vergnaud (1985) that tiers may be conflated in particular languages. In (18) the features [1] and [u] occur on the same tier, which excludes the possiblity of associating a point to both [1] and [u]. If the [1] and [u] are not conflated we create the possiblity of specifying the vowels $/ o /$ and $/ u /$. If on the other ahnd all three Ifnes are conflated we get three vowel systems only having the vowels /i/, /u/, and /a/. Cf. Van der Hulst and Smith (1985). Rennison (1980).

With regard to the issue of underspecification, we hold the view that unpredictarle and predictable features are specified lexically unless they are involved in an alternation. Predictablitty (and corresponding "low cost") is captured by formulating redundancy rules. These redundancy rules may apply in the course of a derivation if their structural description is met. 
Underspecifled segments acquire a full representation then in either of two ways. They may get assoclated to a feature present in the context (either floating or assoclated to som eother skeletal point) or a RR may apply and $f 1 I I$ in a feature.

\section{Tunen}

In this section we will analyse the vowel harmony system of Tunen. This language is spoken in Cameroon in the area surrounding Ndikinimeki (NE of Duala) by approximately 35,000 people. It is a Bantu language, A.44 in Guthrle's classiflcation (see Guthrie, 1967). The avallable data on Tunen are contained in a wordlist and a grammar by Dugast and analysed within a Iinear framework in Mous (1986).

\subsection{Basic facts}

The vowel harmony system of Tunen is of the cross-height type, which is characteristic for West Africa. The harmonic feature is advanced tongue root, [ATR]. A language with classic cross-height vowel harmony has ten vowels. These can be divided on the basis of harmony into two matching sets:

$$
\begin{aligned}
& \text { (19) + ATR: } 1 \text { e A o } u \\
& \text { - ATR: I E a } 0 \text { U }
\end{aligned}
$$

All the vowels within a word are of one set. The dominant value is [+ATR]. A vowel harmony system in which affixes contain only recessive, [-ATR] vowels, is referred to as root control. In other words, only affixes will display alternations in terms of the feature [ATR].

In Tunen, however, suffixes as well as prefixes can be dominant, 1.e. can contain [+ATR] vowels. Tunen lacks /I/ and /V/. Moreover, /e/ does not occur in roots. It does occur in certain prefixes, where it alternates with /if in a dominant (+ATR) environment. In roots and suffixes (and in some prefixes) /E/ alternates with / $1 /$. As a consequence of the merger of /U/ with /o/ there are two possible alternations involving $/ 0 /$. One is the regular alternation $/ 0 /-$ /o/. Which occurs in roots; another is the irregular alternation of $/ 0 /$ in a recessive (-ATR) environment with $/ \mathrm{u}$ in a dominant (+ATR) environment, parallel to the $/ e /-/ 1 /$ alternation. Th1s $/ 0 /-/ 4 /$ alternation occurs in roots, prefixes and suffixes. Roots that contain no other vowels than $/ 0 /$ fall in two categories:

a) Dominant: roots which are themselves invartant, and cause affixes to be $[+\mathrm{ATR}]$.

b) Recessive: roots which do not cause affixes to alter and in which $/ 0 /$ becomes $/ \mathrm{u} /$ in a dominant ( $\mathrm{ATR}$ ) environment.

The alternation /a/ - /A/ Is regular and occurs in roots and prefixes, but there are a few words with /e/ as an optional varlant of /A/, especlaliy before $/ y /$. Thus the harmonic sets of Tunen vowel harmony are:

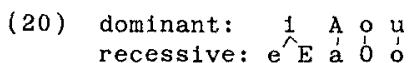

We will now give some examples of these alternations. 
3.1.1. The alternation /a/ - /A/

In verb roots /a/ changes to /A/ if followed by the dominant causative suffix $|-1|$.

(21) falab "to build"

tal "to put down"

bakon "to separate"

fwAlAbi "to cause to build"
tAll "to cause to put down"
bwakunt "to cause to separate"

(labial consonants are rounded before $/ A /$ )

The emphatic demonstrative (nearby) root/tana/ changes to /tina/ after a dominant pronominal prefix.

(22) motana "this', for noun class 1" mutana "this', for noun class 3" batana "this', for noun class 2 " mitAnA "this', for noun class 4 "

The noun class prefix /ma-/ (class 6) changes to /mwA-/ before domfnant noun stems and similarly /ba-/ (class 2) to /bwa-l, e.g.

(23) mabat "clothes" (class 6)

mahok "axes" (class 6)

mwab1l "oll palms" (class 6)

bangot "lizards" (class 2)

balEhan "adv1sers" (class 2 )

mWAkAnu "bellows" (class 6)

bwAsAl un"w1tnesses" (class 2)

bwAlimwAn"servants" (class 2 )

3.1.2. The alternation $/ 0 /-/ 0 /$

The vowel /0/ does not appear in affixes and therefore /0/ alternates with /o/ only in stems; in verb steras before the causative suffix $/-1 /$, and in the stem /-mote/ "one, some" after certain dominant numeral prefixes.

\begin{tabular}{|c|c|c|c|c|}
\hline 24) & $\begin{array}{l}\text { rof } \\
\text { bot } \\
\text { OmotE }\end{array}$ & $\begin{array}{l}\text { "to close a door" } \\
\text { "to start" } \\
\text { "one, dlass } 1 "\end{array}$ & $\begin{array}{l}\text { xof } 1 \\
\text { bot } 1 \\
\text { omot } 1\end{array}$ & $\begin{array}{l}\text { "to cause to close a door" } \\
\text { "to cause to start" } \\
\text { "one, class } 3 "\end{array}$ \\
\hline
\end{tabular}

3.1.3. The alternation /E/ - /1/

The direct [+ATR] ccunterpart of $/ E /, / e /$, does not appear in roots, with a few exceptions, where $1 \mathrm{t}$ is an optlonal variant of /A/. The [+ATR] vowel that alternates with /L/ in roots, however. 1s always /1/. The /E/ in the stem /-motE/ "one, some" changes to /1/ after domlnant prefixes (cf. (24)). In verb roots /E/ changes to $/ 1 /$ if followed by the dominant causative suffix /-i/. For example:

(25) fEf "to blow"

flf 1 "make blow"

In affixes /E/ becomes / $1 /$ after [+ATR] verb stems in the applicative suffix, $/-\mathrm{En} /$, in the stative suffix /-Em/, in the neuter suffix /-E/, in the reciprocal suffix /-Enan/, and before [+ATR] class 19 noun stems in the nominal prefix $/ \mathrm{hE}-1$. 
(26) falabEn "to bu1ld for somebody" fanin folEn "to borrow for somebody" hukin

"to exchange for somebody" hEbOb "ring" (noun class 19) hib1l "to blow for somebody"

"bracelet" (noun class 19)

3.1.4. The alternation $/ e /-/ 1 /$

The vowel /e/ only appears in certain prefixes before [-ATR] stems. It alternates with /1/ before [+ATR] stems.

(27) ebak "tree of savanne" (class 7) 1bwA "husband" (class 7) enEnE "occult power" (class 7) 111k "orphan" (class 7)

There is a tendency towards reharmony in that these noun prefixes containing /e/ have a varlant with /E/ before stems with /E/ as first stem vowel, to a lesser extant before $/ 0 /$, and still more rarely before $/ a /$.

3.1.5. The alternation $/ 0 /-/ u /$

In verb roots $/ 0 /$ alternates with $/ \mathrm{u} /$ if followed by $a[+\mathrm{ATR}]$ suffix.
(28) bol "to disappear" bull "to cause to disappear" hon "to awake" hun1 "to wake up" kolah "to enlarge a hole kulAh1 "Idem, with causative suffix" in a palm wine tree"

In noun prefixes $/ 0 /$ is replaced by $/ u /$ before [+ATR] stems.

(29) mokas "branch" (class 3) munA "grave" (class 3) The verbal separative suffix /-on/ changes to /-un/ after a [+ATR] stem or before the dominant causative suffix $/-1 /$.

$\begin{array}{ll}\text { (30) talon "to Iff" } & \text { tinun "to untie" } \\ \text { tEkon "to throw down" } & \text { bwakunl "to cause to separate" }\end{array}$

That this /o/ belongs to the recessive category can be shown by its complete lack of influence on [-ATR] vowels.

(31) hE+bakton+En $\rightarrow$ hEbakonEn "h1bAkonin "separating instrument" $h E+$ loNom+En $\rightarrow$ hEloNomEn "hiloNomin "telephone recelver"

There are some exceptions to the rule about the vowel of the separative suffix.

(32) fatton+1 $\rightarrow->$ fatont "cause to open" alobotton+1 --> alobotoni "cause to reply to proposal of marriage" 
316 . Nori-alternating $/ 0 /$

in some stems $/ 0 /$ does not alternate. If other vowels cooccur with a non-alternating $/ 0 /$ in a single stem these vowels are [+ATR] and the stem takes $[+A T R]$ prefixes or suffixes.

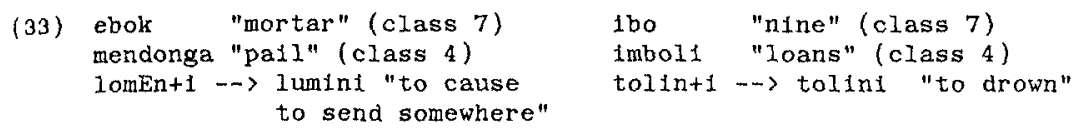

In Just one word, a dominant prefix containing /o/ causes the stem vowels to become $[+\mathrm{ATR}]$ :

(34) Om0te "one, for class 1 nouns" omot1 "one, for class 3 nouns"

In roots contalning only /o/'s, this vowel is clearly represented by two types, as can be seen from (33), $1 . e$. $/ 0 /$ 's that behave as recessive vowels, and non-alternating $/ 0 /$ 's that behave as dominant vowels. 10

\begin{tabular}{|c|c|c|c|c|}
\hline \multirow[t]{3}{*}{ (35) } & kol & $\begin{array}{l}\text { "to go and buy } \\
\text { protective medicine" }\end{array}$ & kol & "to create" \\
\hline & KolEn & $\begin{array}{l}\text { "Idem, with applicative } \\
\text { suffix" }\end{array}$ & kolin & $\begin{array}{l}\text { "Idem, with applicative } \\
\text { suffix" }\end{array}$ \\
\hline & kul1 & $\begin{array}{l}\text { "idem, with causative } \\
\text { suff } 1 x "\end{array}$ & koll & $\begin{array}{l}\text { "1dem, with causative } \\
\text { suffix" }\end{array}$ \\
\hline
\end{tabular}

3.2. Analys $1 \mathrm{~s}$

The vowel system of Tunen is represented as follows:

(36)

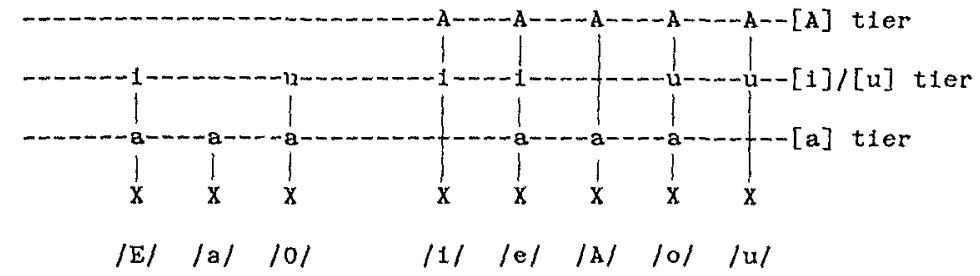

The distribution of features in this diagram shows an interdependence which we can express in the following redundancy rule (RR):

(37)

$*[A]$

[]$\rightarrow[a] / \quad-$

This rule says that the occurrence of [a] is predictable, if there is no floating instance of [A] which contains the relevant skeletal point within its scope. As stated in section 2, rule (37) will apply whenever its structural description is met. It is essential, as will be shown below in sect. 3.2.4. that an occurrence of [A], which is associated to the skeletal point, will not prevent the RR from applying. 
In following sections, we will discuss the data presented in section 3.1 . Each subsection here corresponds to the appropriate subsection of 3.1 .

3.2.1. The alternation $/ a /-\mid A /$

Roots or affixes may contain an instances of a floating [A], which by the association conventions is associated with vowels from left to right:

(38)

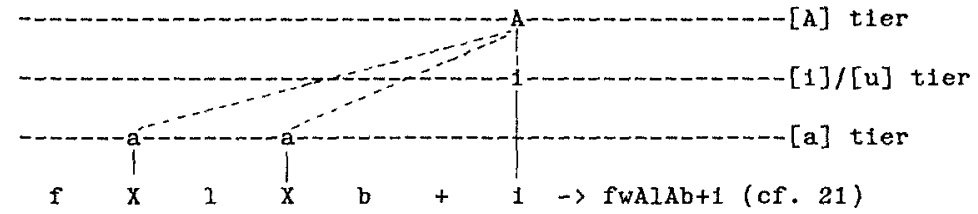

Observe that in this case the $R R$ in (37) is not met. There is a floating instance of $[\mathrm{A}]$.

In the corresponding cases where no morpheme possessing [A] 1s involved, no spreading takes place and the underlying representations are directly phonetically interpreted.

3.2.2. The alternation $/ 0 /-10 /$

This cases is no different from the preceding one. There are, however, no affixes showing this alternation. It occurs only in roots comblned with a dominant affix:

(39)

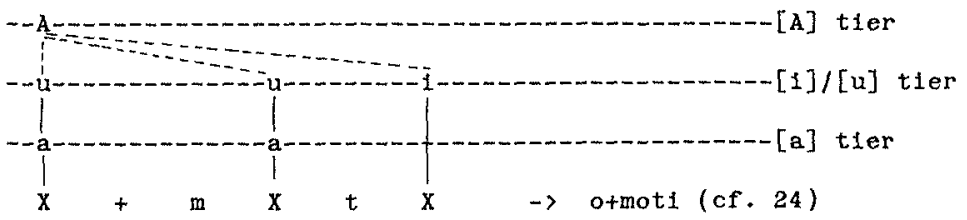

The alternations discussed so far are straightforward and involve nothing but the feature [A]. In the following sections, we deal with cases were the alternation involves a helght difference, alongside or instead of a difference in tongue root position.

3.2.3. The alternation $/ \mathrm{E} /-/ \mathrm{I} /$

The root in (39) alternates with [motE]. The /E/ - /1/ alternation is also found in several suffixes and one prefix. In this case the vowel is left unspecifled for the feature [a], and specified with [1] only. 
If this vowel occurs in an environment where there is no floating instance of [A], RR (37) will apply and insert [a]. This happens in the lefthand example. If, however, there is a floating instance of [A] no [a] is inserted, as in the righthand example:

(40)

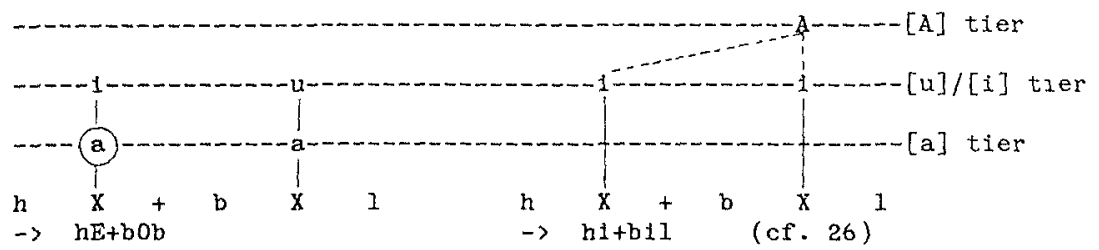

The circled [a] is inserted before spreading has taken place. presumably this ordering is universal. We will assume that RR's, being everywhere rules, always apply before other processes.

\subsubsection{The /e/ - /1/ alternation}

In this type no alternation with respect to tongue root position takes place. In the framework assumed, the feature [A] is specifled underlyingly in this case, since it it not involved in an alternation. Since there is a height alternation, as in the preceding case, we underspecify the vowel for [a]:

In (41) we represent the two relevant cases:

(41)

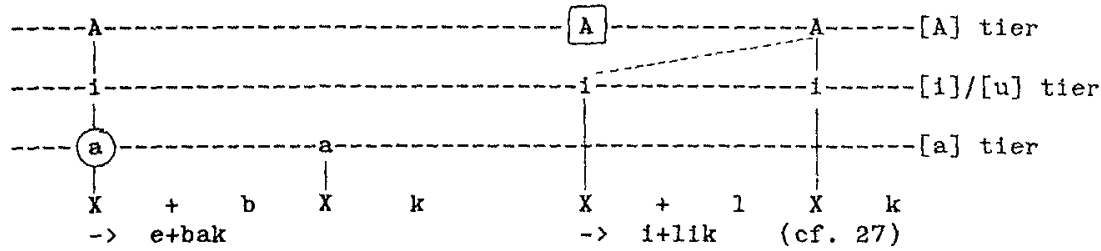

The boxed [A] in the riglit-hand example w11I disappear as a result of the OCP; cf. section 2. In this case, $R R$ (37) will be checked, and found not to be applicable. In the left-hand example, on the other hand, RR (37) is met due to the fact that there is no FLOATING Instance of [A]. An [a] is therefore inserted here. This example shows the cructal importance of the way in which we have formulated RR (37).

3.2.5. The $/ 0 /-1 \mathrm{l} / \mathrm{alternation}$ and a transparency effect

Unlike the $/ e /-11 /$ alternation, which only occurs in prefixes, the present alternation occurs in all morphemlc classes. The analysis is parallel to the le/ - / $1 /$ case. The relevant vowels is left unspecifled for [a], and specified for [u] only. 
(42)

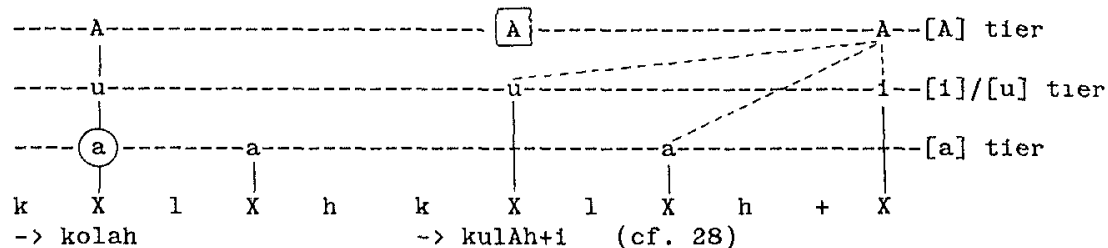

The alternations in this and the preceding section involve segments which are underlyingly associated. In Van der Hulst and Sm1th (1986a) it is shown that this representation is the right one for so called transparent vowels. The term "transparent", as is pointed out, is appropriate to the extent that underlyingly associated features disappear in the context of an adjacent floating occurrence of the same feature due to the OCP. ThIs is shown in the following example:

(43)

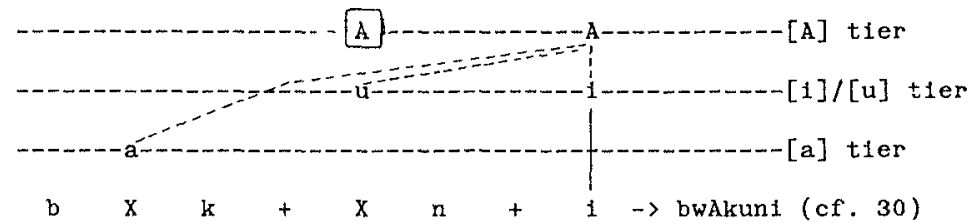

When occurring without an adjacent floating feature, underlyingly associated features stay put. They do not spread since the AC's only apply to floating features. Vowels to their left and right surface with the default value.

3.2.6. The dominant $/ 0 /$

In the preceding section we have seen that some instances of $/ 0 /$ alternate with $/ \mathrm{l} /$. In section 3.2.2. we saw cases where $/ 0 /$ alternated with $/ 0 /$. In both cases the vowels occurred in a recessive morpheme, 1.e. the choice of the alternant depends on the presence of a dominant morpheme. We represented the two vowels as in $(44 a)$ and $(44 b)$ :
(44) a. $10 /-101$
b. $10 /-141$
c. $10 /$
$\left.\right|_{\mathrm{a}} ^{\mathrm{u}}$

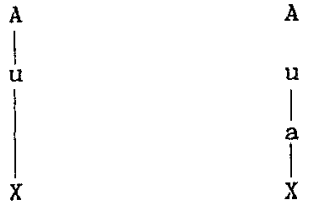

In (44c) we give a third underlying source for $/ \%$. In this case we are dealing with an invariable vowel which is specified as [a], because 1t does not show a height alternation, and belng in a dominant morpheme, it does not show an alternation with respect to tongue root position.

In (45) we give a minimal pair which demonstrates the difference between case $b$ and case $c$ : 
(45)
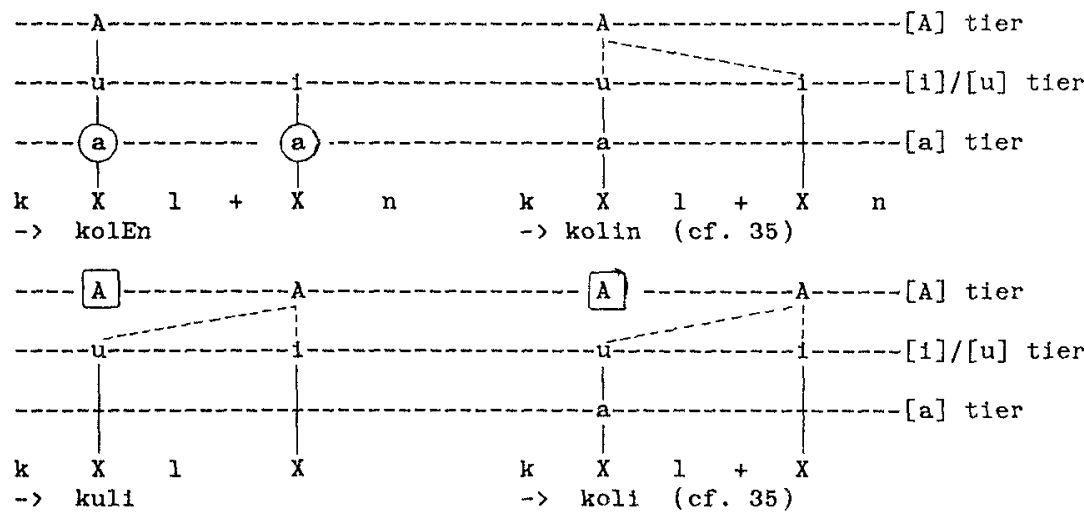

The left-hand examples involve a root with a recessive /o/ which is intrinsically advanced, and unspecified for helght. The right-hand examples involve a root with a dominant $/ 0 /$.

\section{Conclusion}

We have seen that (extra) helght differences can be handled by assuming that $R R^{\prime}$ f 111 in features left unspeclfied, which means that these extra height changes and disharmony effects can be dealt with without making use of dlacritics or abstract vowels. This seems adequate in view of the fact that ATR harmony systems with additlonal height alternations survive the diachronis changes and appear to be relatively stable.

\section{Notes}

1. Harmony systems based is the feature [Advanced tongue root], [Back] and [Round] are quite common. Harmony can also be based on nasality, and, less commonly, on helght, retroflexion, etc. We use traditional binary-valued features here, but wilj adopt another system shortly hereafter.

2. The research that we report here is part of a broader study on the synchronic consequences of vowel shifts on harmony systems. This paper is a fusion of two presentations offered at the 17 th Annual Meeting of the Dutch Linguistic soclety.

3. One and the same language may show the result of different strategies such that one occurs in affixes and another in roots, while different startegles may even be followed as between prefixes and suffixes as in Avatime (Ford 1973). The slternations mentioned in (7) are present in the following african languages: $a-E$ in Ika, $a-0$ in Turkana, $1-e$ in Tunen, $u-o$ in Tunen, a - e In Lelemi, a - o in Masaa1, 1 - E In Lelem1, u - 0 in Lelemi. 
4. Changed vowels continue to behave as if they have not changed. The disharmony remains confined to heteromorphemic disharmony if the merged vowel occurs in a monosyllablc root, or if it coocurs with other merged vowels in a polysyllabic root. One might wonder why disharmony should result from merger? It is a fact that if vowels change class, affixes attached to the roots in which they occur frequently fail to harmonize with the merged vowel. For example, if /I/ goes to /i/ in a monosyllabic root affixes will fail to show up advanced. Simtlarly, if /A/ changes to /E/ affixes may still show up as unadvanced. In this type of case then the disharmony arises across morpheme boundaries only. If the marked vowel occurs with tautomorphemic and unmarked vowels, and changes class, a situation of disharmony inside the morpheme will arise, in addition to heteromorphemic disharmony if the merged vowel occurs in a peripheral syllable. Again it appears to be a fact that if one of the root vowels changes class, other vowels usually remain as they were, 1.e. no harmonic adjustment is made.

5. A remark in order. Neutrality may occur even if the harmonic counterpart st111 exists. We know cases in whlch harmony systems are "obscured" by the presence of vowels which, although they do not have a predictable value for the harmonic feature, stili fall to harmonize, either in particular morphemes, or everywhere, and again such segments may behave as transparent or opaque, Vowels of this type then are neutral without there being a neutralization of an opposition. For want of a better term we will refer to such vowels as pseudo-neutral segments in those passages where we explicitly want to refer to them. It seems reasonable to assume that pseudo-neutrality efther results if a merger is taking plece, but has not yet effected all occurrences of the relevant vowel, or when the lost vowel reappears marginaliy in loans.

6. In addition to this Vago argues that the treatment of opaque segments also calls for tier duplication.

7. As has been pointed out by Lleber, Iier Duplication, has not only been proposed in the study of vowel harmony. From work in the area of non-concatenative or associative morphology, we know that tiers can be multiplicated if they correspond to different morphemes. Clearly then, our dismissal of tier duplication in phonology is meanlngless, if we cannot also show that TD in morphology can be dispensed with. We believe that this is possible, and refer to Van der Hulst and Smith (1986c) for an exposition of our view.

8. A comparable assymmetry as that observed in ATR systems may exist in front-back harmony, 1.e. neutral segments may be [-BACK] or [+BACK]. The data avallable to us suggests that in segments of this type front neutral segments may be elther transparent or opaque, whereas back neutral segments may only be opaque.

9. It is clear that conventions which repair OCP violations should be stated explicitly. HS propose that floating autosegments absorb bound autosegments rather than vice versa ("packman convention").

10. Due to this double nature of /o/'s there is some confusion in the system, as can be seen in (33) and in the following examples.

$$
\begin{array}{cll}
\text { lobon "to weed" } & \text { lobon+En } \rightarrow \text { lobonEn, but: loboxi+1 } \rightarrow \text { lobuni } \\
\text { sokom } & \text { to work } & \text { sokom+En } \rightarrow \text { sokomin, but: sokom }+1 \rightarrow \text { sukum } 1 \\
& \text { in valn" } &
\end{array}
$$


References

ARCHANGELI, D.

1985 Yokuts harmony: evidence for coplanar representation in Non-linear phonology. LI 16, p. $335-372$

BENNIS, H and F. BEUKEMA (eds.)

1985 Linguistics in the Netherlands 1985, Foris, Dordrecht

BOOY, G.E.

1984 Neutral vowels and the autosegmental analysis of Hungarian vowel harmony. Linguist1cs 22 , p. 629-664

DUGAST, I.

1967 Lexique de la langue tunen, Langues et Litt'eratures de I'Afrique noire 2 , KIIncksieck, Paris

1971 Grammalre du Tunen, Langues et L1tt'eratures de 1'Afrique notre 7 , Klincksieck, Paris

EWEN C. and H.G. van der HULST

1985 Single-valued features and the non-linear analysis of vowel harmony, in Bennis and Beukema (1985), p. 39-48

FORD, K.C

1973 On the loss of cross-helght vowel harmony, Research Review suppl.4, p. 50-80, Institute of African Studies, Legon

GUTHRIE, M.

1971 Comparative Bantu 2, Gregg Int. Publ, Westmead

HALLE, $M$ and $J . R$. VERGNAUD

1981 Harmony processes, in W. Klein and W. Levelt (eds.)Crossing the boundaries in linguistics, Reidel, p. 1-22

HULST, H.G. van der and N. SMITH

1982 Prosodic domains and opaque segments in autosegmental theory, in H.G. van der Hulst and N. Spsth (eds.) The structure of phonological representations 2, Foris, p. 311-464

1985 Vowel harmony in Dflng111, Nyangumarda and Warlpiri, in The Phonology Yearbook2

1986 a On Neutral Vowels, In K. Bogers, H. van der Hulst and M. Mous (eds.), The phonological representation of suprasegmentals, For 1s, p. 233-279

$1986 \mathrm{~b}$ On some non-African ATR-based harmony systems ms.

$1986 \mathrm{c}$ Against tier duplication ms.

KAYE, J., J. LOWENSTAYM and J.R. VERGNAUD

1985 The internal scructure of phonological elements: A theory of charm and government, Phonology Yearbook (1985)

LIEBER, R .

1985 An integrated theory of autosegmental processes, ms.

MOUS, M.

1983 Vowel harmony in Nen (Bantu A.44), ms. 
MOUS, $M$.

1986 Vowel Harmony in Tunen, in K. Bogers, H. van der Hulst and M. Mous (eds.) The phonological representation of suprasegmentals, For 1s, 281-295

RENNISON, J .

1985 Tridirectional vowel features and vowel harmony, $\mathrm{ms}$.

STEWART, J.M.

1971 Niger-Congo, Kwa, in Current trends in lingulstics 7: Linguistics in Sub-Saharan Africa, Mouton, p. 179-212

SVANTESSON, J.O.

1986 Vowel harmony shift in Mongolian, in Lingua 67, 283-327

VAGO, R.

1984 Morpheme level harmony in a mult1-leveled autosegmental framework, ms.

WILLIAMSON, K.

1973 Some reduced vowel harmony systems, In Research Notes, p. 145-169

1984 Vowel merger in harmony languages, in JOLAN 2, p. 61-82 